\title{
Neutron Diffraction and Mossbauer Effect Study of a Cobalt Substituted Zinc Ferrite
}

\author{
by \\ M. K. Fayek*, A. A. Bahgat, Y. M. Abbas and L. Moberg \\ Atomic Energy Establishment, Cairo, Egypt \\ and \\ Institute of Physics, Stockholm, Sweden.
}

\begin{abstract}
The mixed cubic ferrite $\mathrm{Zn}_{0.85} \mathrm{Co}_{0.15} \mathrm{Fe}_{2} \mathrm{O}_{4}$ is studied by neutron diffraction and Mossbauer effect techniques at the temperature range $4.2-293{ }^{\circ} \mathrm{K}$. The obtained spectra by both methods at low temperature show a long range magnetic ordering. The neutron pattern at $4.2^{\circ} \mathrm{K}$ is successfully indexed on the basis of a magnetic unit cell obtained by doubling the chemical unit cell in one direction. A non collinear model is proposed for the magnetic structure of this compound. The Mossbauer effect data favour the proposed model and indicate that the magnetic moments are aligned at an angle of about $55^{\circ}$ relative to the [112] direction in the magnetic unit cell.

*Present address : Qatar University, Doha, Qatar.
\end{abstract}


Fig. 1: Neutron diffraction pattern of $\mathrm{Zn}_{11.85} \mathrm{Co}_{0.15} \mathrm{Fe}_{2} \mathrm{O}_{4}$ at liquid helium temperature. The indices based on the cubic chemical unit cell.

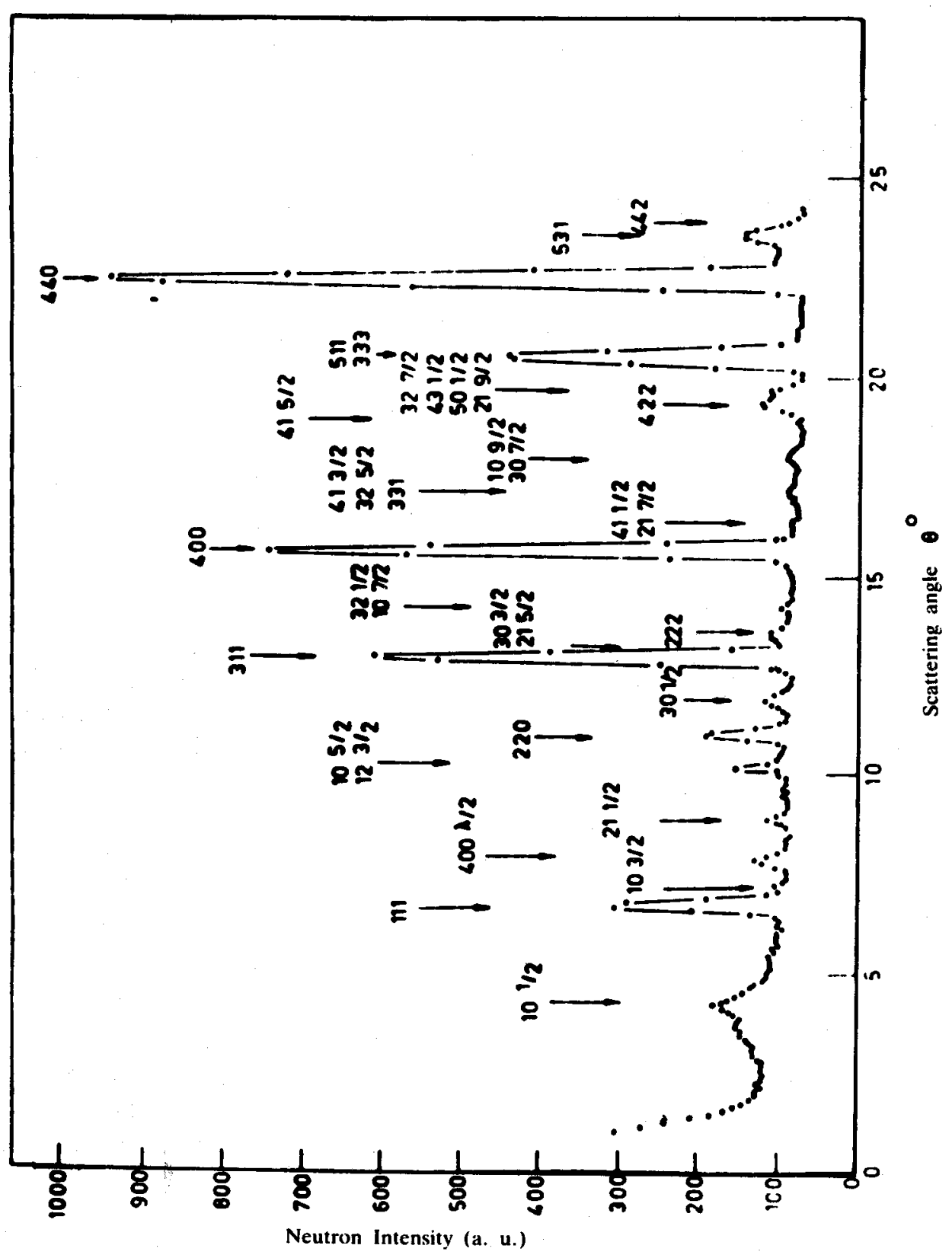




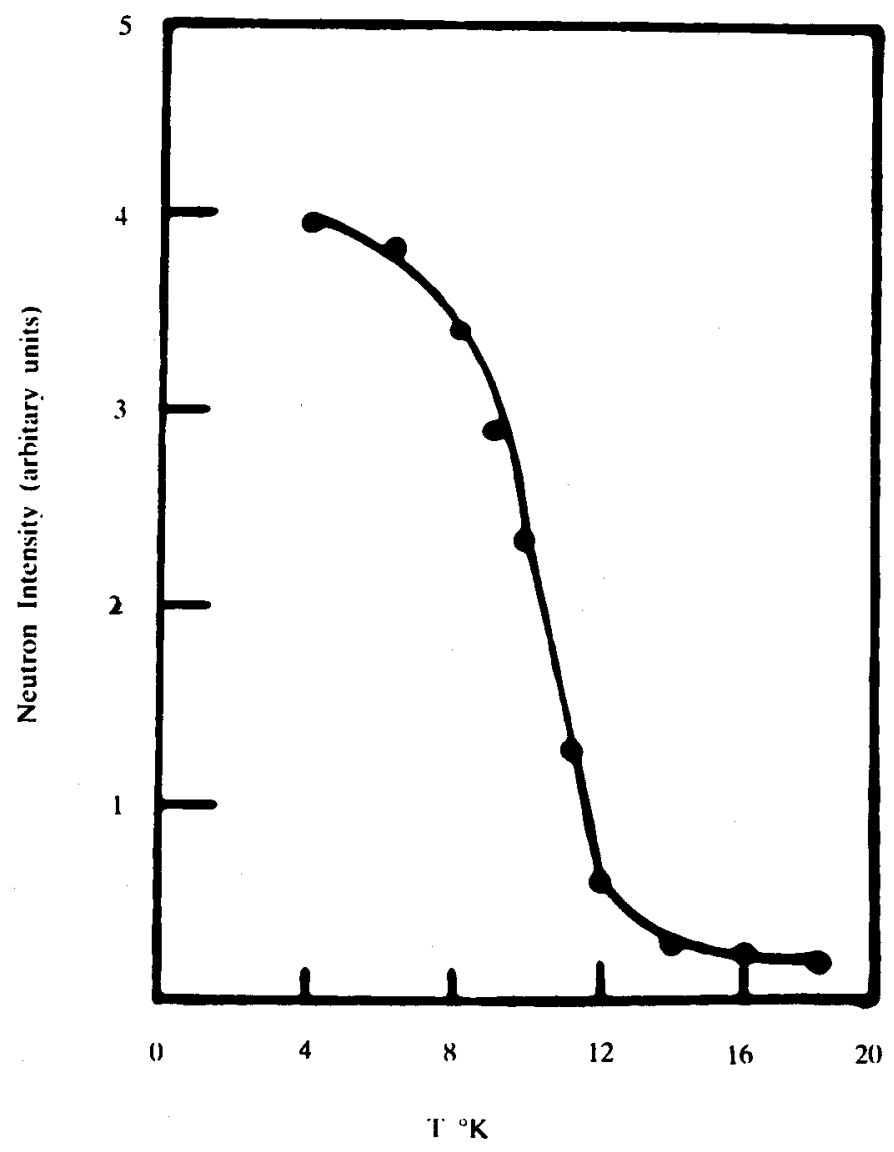

Fig. 2: Temperature dependence of the peak height of the principal magnetic reflection $M\left(10 \frac{1}{2}\right)$.

Mossbauer resonant absorption spectra of the studied compound was taken at room temperature (Fig. 3) and $77^{\circ} \mathrm{K}$ using a time mode Mossbauer effect spectrometer of the constant acceleration driving system coupled to 1024 channels multichannel analyzer. The calibration of the spectrometer was carried out from spectra iron oxides and metallic iron. The absorber contained approximately 0.5 $\mathrm{mg} \mathrm{Fe}^{57} / \mathrm{cm}^{-2}$. 


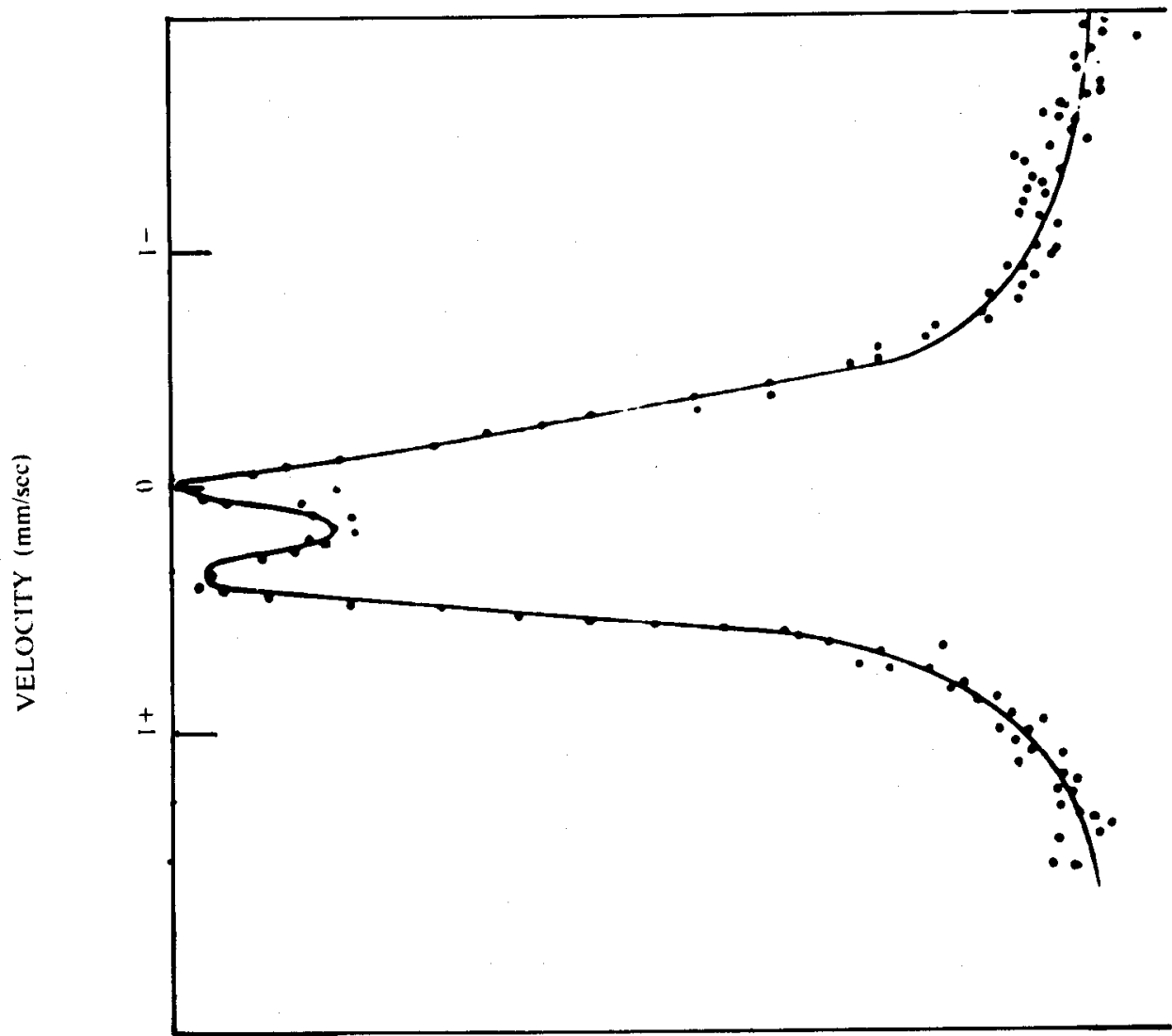

Fig. 3: Mossbauer effect spectrum of $\mathrm{Zn}_{0.85} \mathrm{Co}_{0.15} \mathrm{Fe}_{2} \mathrm{O}_{4}$ at room temperature.

The used source was $50 \mathrm{~m} \mathrm{Ci} \mathrm{Co}^{57}$ diffused in $\mathrm{Rh}$ matrix. On the other hand Mossbauer effect patterns at $4.2^{\circ} \mathrm{K}$ were obtained, where the absorber was mounted on the end of a cold finger of a liquid helium cryostat and the source was maintained at room temperature. Measurements were also undertaken at $4.2{ }^{\circ} \mathrm{K}$. Where applied longitudinal magnetic field of $15 \mathrm{KOe}$ (parallel to the $\gamma$-ray propagation was applied to the absorber. The solid lines through the data points are the results of a least squares fit to the data of the two mixed magnetic dipole and electric quadrupole $\mathrm{Fe}^{57}$ hyperfine patterns. The determined ME parameters are collected in table 1. 
Table 1

\begin{tabular}{|c|c|c|c|c|c|c|}
\hline $\begin{array}{c}\text { Temperature } \\
{ }^{\circ} \mathrm{K}\end{array}$ & $\begin{array}{c}\text { Isomer Shift } \\
\mathrm{mm} \mathrm{s}^{-1}\end{array}$ & $\begin{array}{c}\text { Quadrupole } \\
\text { Splitting } \\
\begin{array}{c}\Delta E=1 / 2 e^{2} q Q \\
m m s^{-1}\end{array}\end{array}$ & $<$ & $\begin{array}{l}\text { Quadrupole Shift } \\
>=\underset{m m}{1 / 8 \mathrm{e}^{2} Q} q\left(3 \cos ^{2} 0-1\right)\end{array}$ & $\begin{array}{l}\text { Magnetic Hyperfine } \\
\text { field } \mathrm{kOe}\end{array}$ & $\begin{array}{l}\text { Line width of } \\
\text { the two high } \\
\text { energy peaks } \mathrm{mm} \mathrm{s}^{-1}\end{array}$ \\
\hline 300 & 0.169 & 0.338 & & & & \\
\hline 4.2 & 0.272 & $\longrightarrow$ & & -0.128 & 517 & 0.595 \\
\hline $4.2+15 \mathrm{KOe}$ & 0.272 & $\longrightarrow$ & & -0.215 & 512 & 0.590 \\
\hline
\end{tabular}
Errors
$\pm 0.0817$
$\pm 0.0204$
$\pm 0.0204$
$\pm 2.5$
$\pm 0.0817$ 


\section{Results and Discussion}

\section{(i) Crystallographic parameters}

The sample has a cubic spinel type crystal structure in which the oxygen ions form a fcc. packing. The space group is $\mathrm{F} \mathrm{d} 3 \mathrm{~m}$ no 227 (11). The cations with the tetrahedral coordination are in 8 (a) lattice sites, those with the octahedral are situated in the 16 (d) positions. The oxygen ions are in the 32(e) lattice sites with an oxygen parameter $=0.375$ for a perfect closed-packed arrangement. In the course of refinment, considering the strong preference of $\mathrm{Zn}^{2}$ ions for the tetrahedral coordination because of their tendency to form covalent bonds involving sp ${ }^{3}$ orbitals. It is assumed that all the $\mathrm{Zn}^{2}$ ions are localised on the A-sites (12). There is a combination of six nearest neighbours of an iron octahedral ion consisting of three kinds of ions $\left(\mathrm{Co}^{2}\right.$, $\mathrm{Zn}^{2}$ and $\mathrm{Fe}^{3}$ ) distributed randomly over A-sites, then we write the cation distribution of ions over lattice sites in the form:

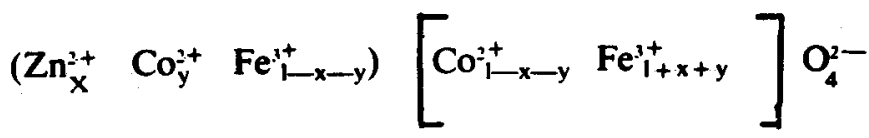

where the round brackets include ions lying in tetrahedral sites and the square brackets include ions occupying octahedral sites. So assuming that the substitution cation statistically replaces $\mathrm{Fe}^{3}$, the intensities were calculated as functions of the mean oxygen parameter and the cation distribution parameter defined as the percentage of substitution cations occupying the octahedral $\mathrm{B}$ - sites of the spinel structure. The conventional reliability factor $\mathrm{R}$ was minimized by a systematic veriation of the above parameters using a computer program (13). Coherent neutron scattering amplitudes as reported by Bacon (14), were used in calculations.

In order to reduce the influence of the Debye-Waller correction, nuclear intensities obtained at $4.2{ }^{\circ} \mathrm{K}$ were taken for the determination of the two characteristic parameters of the $\mathrm{Zn}$-Co-ferrite spinel unit cell. The lowest value for the reliability factor $R=0.025$ has been obtained with the oxygen parameter $=0.3854 \pm 0.0001$ and for half of the coblat ions in the tetrahedral positions. Quantitatively the cation distribution formula is then:

$$
\mathrm{Zn}_{0.85}^{2+} \mathrm{Co}_{0.08}^{2+} \mathrm{Fe}_{1.07}^{3+}\left[\mathrm{Fe}^{3+.95} \mathrm{Co}_{0.07}^{2+}\right] \mathrm{0}_{4}{ }^{2-}
$$


It should be emphasized however, that for the cobalt ions in the octahedral positions the $\mathrm{R}$ factor increases to 0.038 only.

This fact does not permit to find precisely the distribution of cobalt ions in this compound, where it suggests that $\mathrm{Co}^{2}$ ions have no preference for either site, although in $\mathrm{Co}^{2} \quad \mathrm{Fe}^{3}{ }_{2} \quad \mathrm{O}_{4}^{2}$ the $\mathrm{Co}^{2}$ ions preferentially occupy the octahedral sites (15).

The ME spectrum at $293^{\circ} \mathrm{K}$ (Fig. 3) shows a quadrupole doublet. From the fact that no internal magnetic hyperfine field is seen, it is apparent that the Larmour frequency of this composition is much smaller than the spin flip-flop frequency. One should anticipate three lines. One dus to tetrahedral $\mathrm{Fe}^{3}$ (where there is a cubic symmetry around that site) and the other two as a quadrupole doublet due to the $\mathrm{Fe}^{3}$ at the octahedral site, where the octahedron around the $\mathrm{B}-$ site, however elongates along [111] direction, there by establishing an electric field gradient at the $\mathrm{B}-\mathrm{site}^{\mathrm{Fe}}{ }^{3}$. In the present spectrum (Fig. 3) no line due to $\mathrm{Fe}^{3}$ at tetrahedral site was observed. This is perhaps due to the fact for large concentration of $\mathrm{Zn}$, very little iron is left at tetrahedral site in agreement with the obtained cation distribution formula. Therefore any small amount of iron left at the tetrahedral siite would give a very faint signal which can be easily overshadowed by the quadrupole doublet due to the octahedral $\mathrm{Fe}^{3}$ site.

\section{(ii) The magnetic structure}

The neutron diffraction spectrum obtained at $4.2^{\circ} \mathrm{K}$ with the sample contained in a vanadium container is shown in figure 1 . It is characterised by a number of peaks which did not appear in the room temperature pattern. They could be readily indexed on the basis of a magnetic unit cell $(a, a, 2 a)$ derived by doubling the chemical unit cell in one direction.

No contamination (in the limits of error) of the nuclear peaks by magnetic contribution was observed i.e. the presence of co-existing ferri and antiferromagnetic ordering is not expected as reported previously for neutron diffraction measurements at $4.2^{\circ} \mathrm{K}$ on $\mathrm{Zn}_{\mathrm{x}} \mathrm{Mn}_{1-\mathrm{x}} \mathrm{Fe}_{2} \mathrm{O}_{4}$ with $\mathrm{x}$ in between 0.82 and 0.87 (1), and also for Mossbauer effect measurements at $7^{\circ} \mathrm{K}$ on $\mathrm{Zn}_{\mathrm{x}}$ 
$\mathrm{Ni}_{1-\mathrm{x}} \mathrm{Fe}_{2} \mathrm{O}_{4}$ with $\mathrm{x} 0.9$ (2). The observed magnetic indices obey the rule $\mathrm{h}+\mathrm{k}+\mathrm{l}=2 \mathrm{n}$ with 1 odd only.

It can be proved that the absence of the reflections with even is solely due to the presence of antiferromagnetic ordering in both tetrahedral and octahedral sublattices. It follows further that the same spin direction is associated with $\mathrm{x}$, $y, z$ and $x+1 / 2, y+1 / 2, z+1 / 2$ positions. The ions in the sites with $x, y, z$ and $x, y$, $z+1 / 2$ have opposite spin alignment. Thus for the analysis of all possible arrangements of + and - spin directions, it is sufficient to consider 8 octahedral and 4 tetrahedral sites. A preliminary survey of magnetic structures including magnetic order in the B as well as A site showed that any ordering in the $\mathrm{A}-$ sites has a small influence on the agreement between the observed and calculated magnetic intensities. This could be expected in view of a large concentration of the diamagnetic ions in the tetrahedral positions.

Therefore the number of models has been reduced by neglecting the long range magnetic order in the A sublattice. A convenient description of the obtained magnetic structure which gave a minimum value for the reliability factor $6 \%$ could be achieved by grouping the spins with the same sign in four sublattices each containing the sites with :-

$$
\begin{aligned}
& x, y, z ; \bar{x}, \bar{y}, z ; \bar{y}, x, 1 / 2-z ; y, \bar{x}, 1 / 2-z ; \\
& +(0,0,0) \text { and }(1 / 2,1 / 2,1 / 2) \text { where } \\
& x, y, z \text { are as follows (see figs. } 5 \& 6 \text { ) }
\end{aligned}
$$

\begin{tabular}{ccccc}
\hline Sublattice & $x$ & $y$ & $z$ & Spin sign \\
\hline I & $1 / 8$ & $1 / 8$ & $5 / 16$ & + \\
II & $1 / 8$ & $1 / 8$ & $13 / 16$ & - \\
III & $1 / 8$ & $5 / 8$ & $9 / 16$ & + \\
IV & $1 / 8$ & $5 / 8$ & $1 / 16$ & + \\
\hline
\end{tabular}


The zero field Mossbauer effect spectra of $\mathrm{Zn}_{0.85} \mathrm{Co}_{0.15} \mathrm{Fe}_{2} \mathrm{O}_{4}$ obtained at $4.2{ }^{\circ} \mathrm{K}$ (Fig. 4) showed a magnetic transition, and consisted of six absorption lines.

Fig. 4: Mossbauer effect spectrum obtained at $4.2 \mathrm{~K}$ for $\mathrm{Zn}_{0.85} \mathrm{Co}_{0.15} \mathrm{Fe}_{2} \mathrm{O}_{4}$.

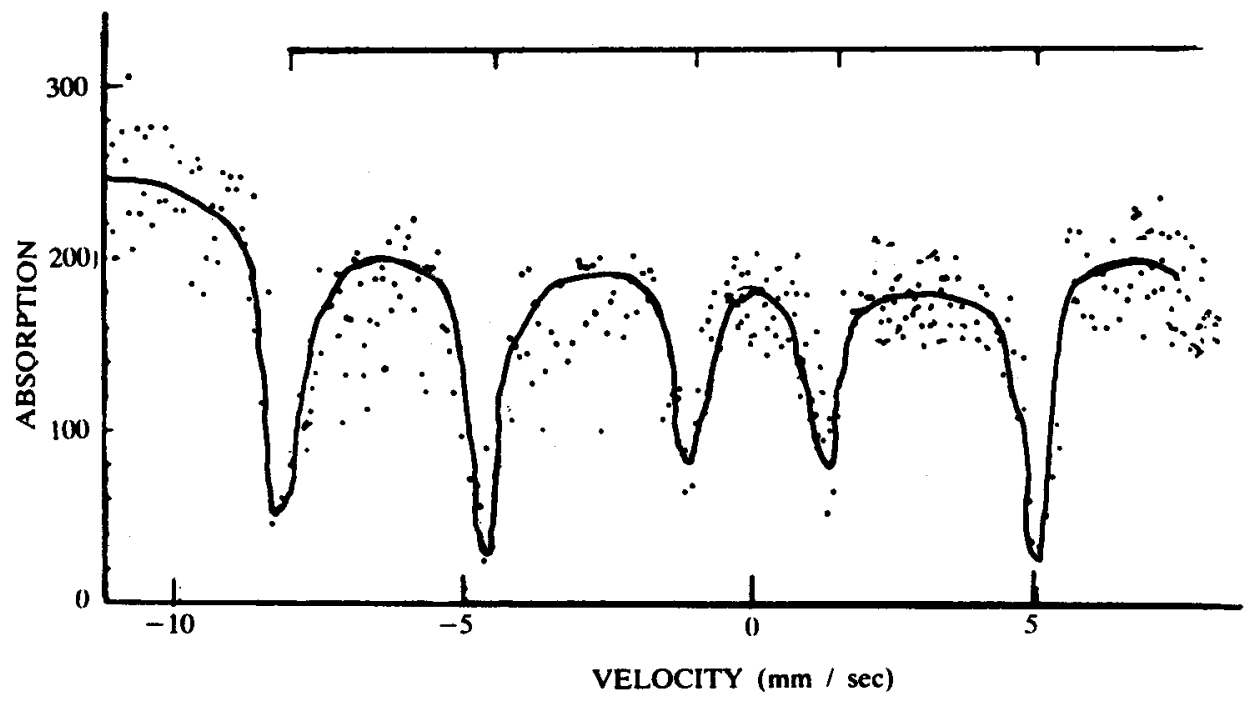




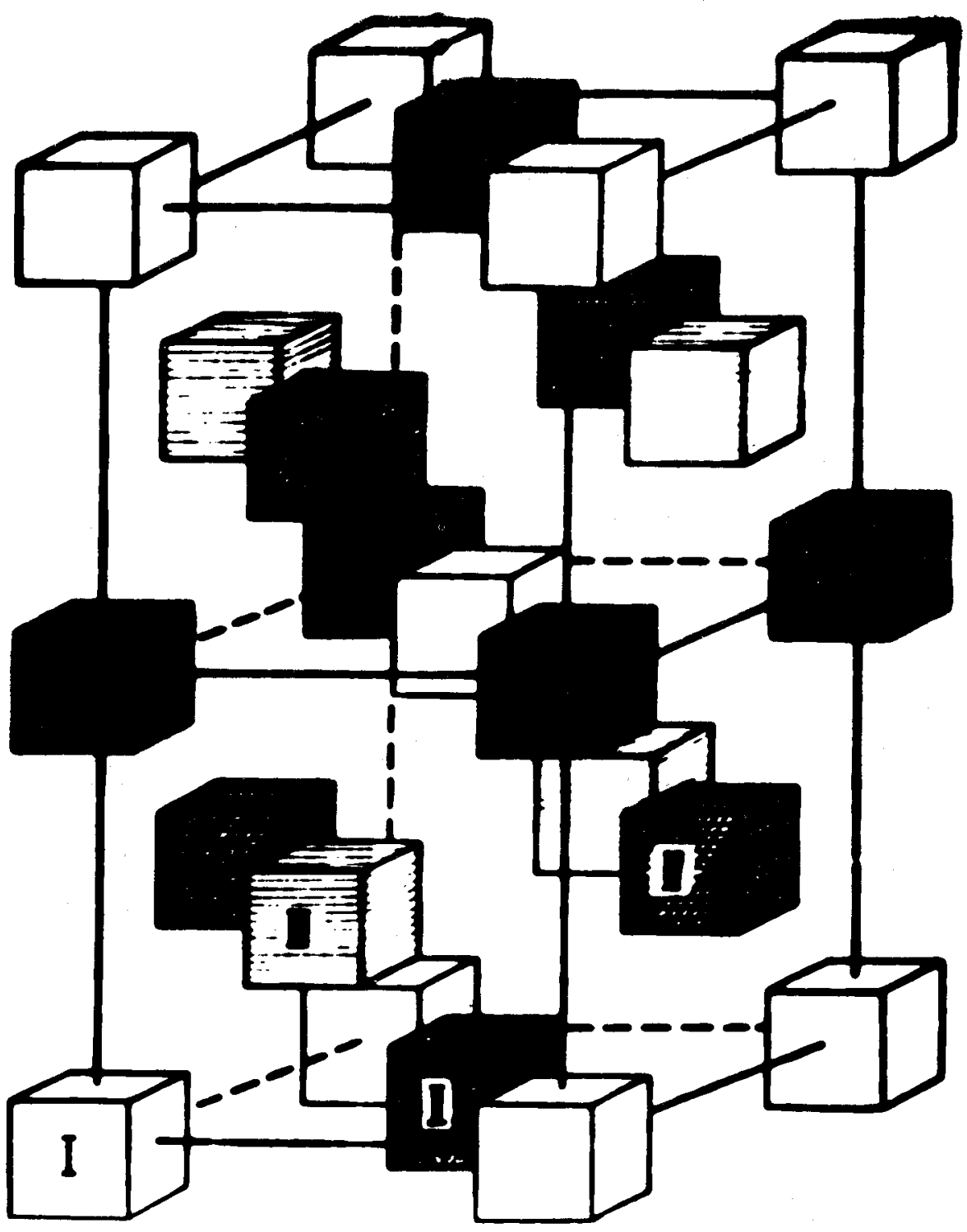

Fig. 5: The magnetic sublattices in the $\mathrm{Zn}_{\mathrm{O} .85} \mathrm{Co}_{0.15} \mathrm{Fe}_{2} \mathrm{O}_{4}$ magnetic unit cell. 


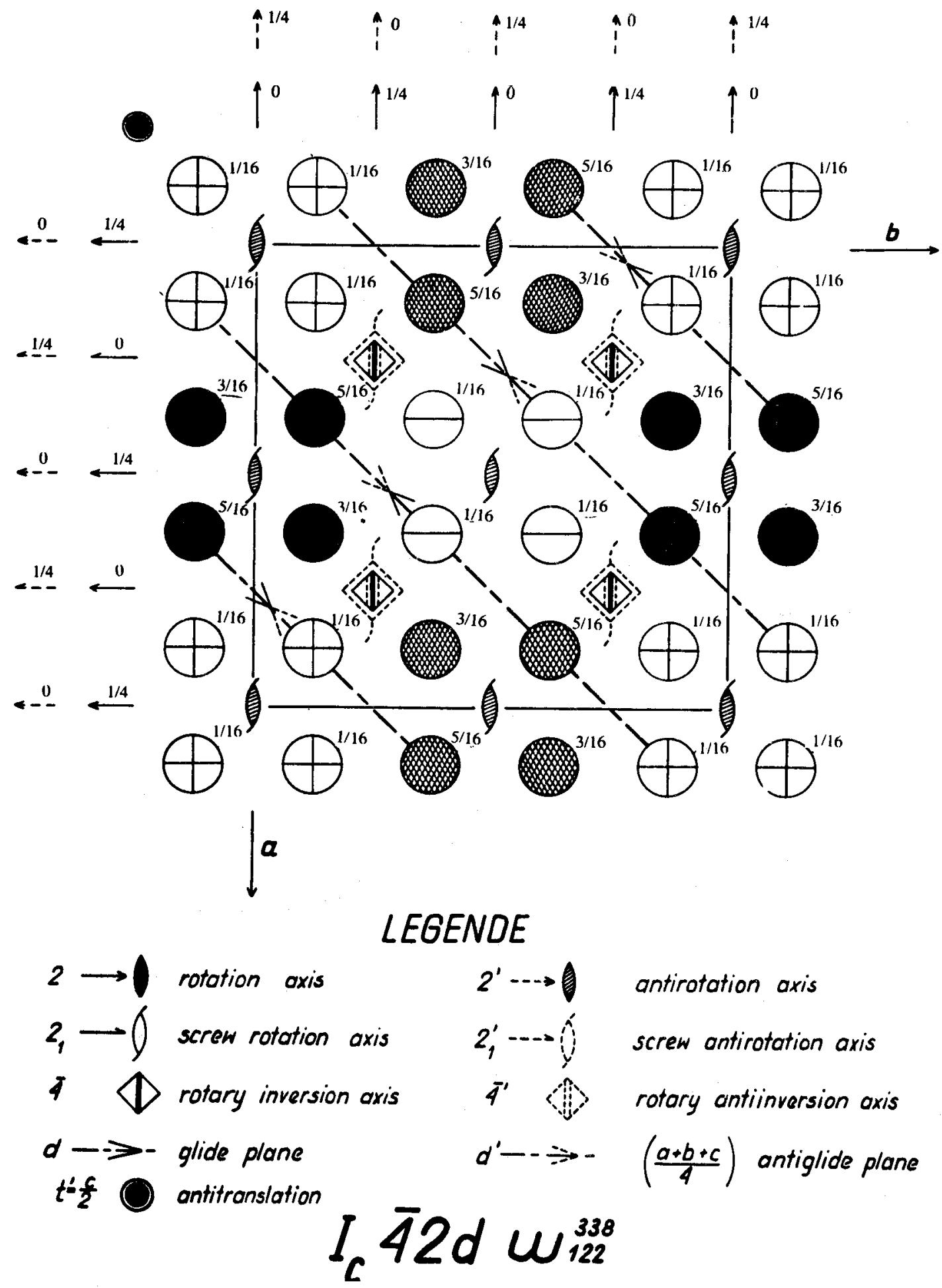

Fig. 6: The magnetic unit cell of $\mathrm{Zn}_{\mathrm{O} .85} \mathrm{Co}_{0.15} \mathrm{Fe}_{2} \mathrm{O}_{4}$. 
The determined Mossbauer effect parameters are collected in Table 1. The line widths are wider than could be expected for a simple uniaxial antiferromagnet. Since the structure seemed to consist of four sublattices, it is possible that line broadening may result from variations in the electric quadrupole interactions. The obtained non zero value of the quadrupole shift $(\triangle \mathrm{Q})=-0.128 \mathrm{~mm} \mathrm{~s}^{-1}$ of the absorption lines is hardly compatible with a collinear spin arrangement and favours a non collinear model with an angle of the electric field gradient EFG and the spin moments. Both obtained values of the quadrupole displacement at the paramagnetic and antiferromagnetic states were used to calculate such angle, which was found to be $55^{\circ}$. This is in agreement with that determined from the present neutron measurements, where the spins are aligned parallel to [112] direction in the magnetic unit cell. The obtained value of effective magnetic field $\mathrm{H}_{\text {eff }}$ is les than that reported for the stoichiometric $\mathrm{Co} \mathrm{Fe}_{2} \mathrm{O}_{4}(15)$. The decrease would appear to be due to the decrease in the transferred hyperfine field when $\mathrm{Fe}^{3}$ ions on $\mathrm{A}$ - sites are replaced by diamagnetic $\mathrm{Zn}^{2}$ ions.

\section{Conclusions}

a) The obtained neutron diffraction pattern of $\mathrm{Zn}_{0.85} \mathrm{Co}_{0.15} \mathrm{Fe}_{2} \mathrm{O}_{4}$ at $4.2 \mathrm{~K}$ showed magnetic peaks with indices hk $\ell / 2$ with $\ell$ and $h+k$ odd only, where $\mathrm{hk} \ell$ are the indices for the spinel type unit cell. The absence of the magnetic contribution in the reflections with 1 even indicates the antiferromagnetic type of ordering. The magnetic ordering in the B - sites can be described in terms of four sublattices I, II, II, and IV. The sublattices (I, II) and (III, IV) have opposite spin alignment.

b) Well shaped Zeeman spectrum for the compound $\mathrm{Zn}_{0.85} \mathrm{Co}_{0.15} \mathrm{Fe}_{2} \mathrm{O}_{4}$ was obtained at $4.2 \mathrm{~K}$, the more broadening of the outer lines could be attributed to a supermagnetic behaviour. This is in agreement with the obtained neutron diffraction results, where the presence of the broad lines (fig. 1) indicating a short range order, for example the magnetic reflection $\mathbf{M}$ $\left(10 \frac{1}{2}\right)$, is absorbed in an enlarged diffuse peak with a broad hump. Such liquid type peak could suggest that the long range magnetic order, both in tetrahedral and octahedral sites, is still not complete at $4.2 \mathrm{~K}$ (partial disorder) i.e., it appears to be connected with a partial replacement of $\mathrm{Fe}^{3}$ ions in the octahedral sites by cobalt cations. 
c) For the sample under study we established the percentage of ion at tetrahedral sites as around $7 \%$. The presence of iron ions at tetrahedral sites should evidently lead to a corresponding change in the composition of the nearest neighbours of $\mathrm{Fe}^{3}$ ions lying at octahedral sites and increase the number of possible combinations of the short range surroundings of these ions.

d) Since the angle between the hyperfine field and the principal axis of the electric field gradient tensor may be different for each sublattice, and where also there is ferric ions on A and B sublattices, it is therefore particularly important to examine the ME spectra in applied field. In fact the in field spectrum with an external magnetic field of $15 \mathrm{kOe}$ was not sufficient to have a reasonable effect and it seemed that the application of a larger magnetic field will be helpful.

e) One interesting result of the present study for the composition $\mathrm{Zn}_{0.85} \mathrm{Co}_{0.15}$ $\mathrm{Fe}_{2} \mathrm{O}_{4}$ is that the neutron diffraction pattern at $4.2 \mathrm{~K}$ showed the same magnetic peak distribution as in the case of stoichiometric $\mathrm{Zn} \mathrm{Fe} \mathrm{O}_{4}$, however the superstructure lines are not so well developed. This suggests that the antiferromagnetic structure of $\mathrm{Zn} \mathrm{Fe}_{2} \mathrm{O}_{4}$ is still preserved even after replacing the zinc cations with $15 \%$ of cobalt.

f) In view of ambiguities, inherent in the present powder experimental data, a search for more complex structures is not considered to be worth while. A detailed study of the magnetic structure of such compound would require the collection of more complete experimental data available only from single crystal. Moreover if the sample was made with iron enriched in the isotope $\mathrm{Fe}^{57}$, the lines of Mossbauer spectra would possess larger relative absorptions. It may then be possible to decipher finer details in the spectra. The additional information obtained may lead to the development of a more defined model.

g) Another point is that, the Neel temperture is only $12 \mathrm{~K}$ for the studied compound, therefore the magnetic field interaction will be comparable to the superexchange interactions. It would be of interest to have the neutron diffraction studies extended to include the presence of a large external magnetic field. 


\section{REFERENCES}

1. G. Koczarow, J. Leciejwicz, M. Fayek and A. Murasik Phys. Stat. Sol. 4,53, 1970.

2. L. Leung, B. Evans and A. Morrish. phys. Rev. B 8, 291973.

3. R. Gupta and R. Mondiratta. J. Appl. Phys. 48, 845, 1977.

4. J. Smit and H. P. Wijn. Ferrites Eindhoven 1959.

5. Y. Yafet and C. Kittel. Phys. Rev. 87, 290, 1952

6. G. A. Petit and D. W. Forester. Phys. Rev. B 4, 3912, 1971.

7. A. H. Morrish. The 3rd International Conference on Ferrites Kyoto Japan, 1980.

8. M. K. Fayek, A. A. Bahgat and Y. M. Abbas. Atomkernenergie 26, 285, 1975.

9. B. Boucher, R. Buhl and M. Perrin. Phys. Stat. Sol. 40, 171, 1970.

10. U. Konig, E. F. Bertaut, Y. Gros and G. Chol, J. de Physique 32, 3201971.

11. K. Lonsdale. International Tables for $\mathrm{X}$-ray crystallography. I Birmingham Kynoch press 1952.

12. J. B. Goodenough and A. L. Loeb. Phys. Rev. 98, 391, 1955.

13. M. K. Fayek and A. I. Elsherif. ARE. AEE Rep. 204, 1974.

15. G. E. Bacon. Acta Cryst. 25, 391, 1969.

15. G. A. Sawatzky, F. Vanderwoude and A. H. Morrish. Phys. Rev. 187, 747, 1969. 


\section{دراسة حديديات الزتك والكـوبالت بـاستخدام ظـاهرتى الحيـود

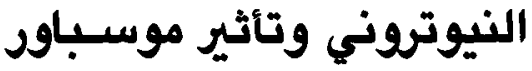

$$
\text { محمد خورشيد فايق ـ علاء الدين بهجت ـ يحيى عباس ـ ل ـ موبرج }
$$

9

معهد الفيزيـاء بالســويد

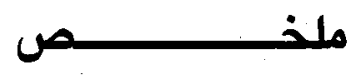

لقد تم دراسة حديديات الزنك والكويالت باستخدام ظاهرتى الحيود النيوتروني

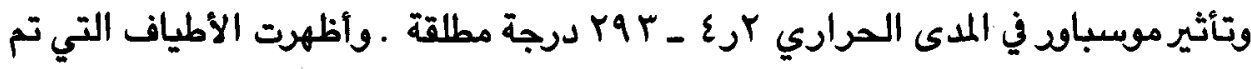

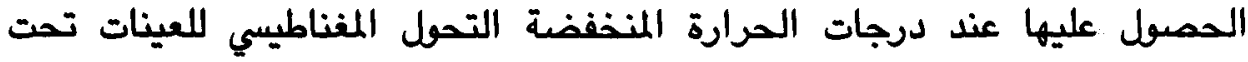
الدراسة وقد تبين من دراسة نموذج الحيود النيوتوني عند درجة حرارة الهليوم العيه السائل برع درجة مطلقة أن الخلية المفناطيسية تعادل ضعف الفين الخلية الكيمائية وقد أمكن الحصول على موديل يصف ترتيب الحركة المغزلية داخل وحدة الخلية المغناطيسية 